\title{
IMPACT OF CULTURAL ADVERTISEMENTS ON ATTRIBUTES TOWARDS BRAND, ADVERTISING AND PURCHASE INTENTIONS
}

\author{
AYESHA AMJAD \\ Ph. D. Scholar of Business Administration, \\ The Superior University, Lahore, Pakistan \\ HAFIZ SAQIB MEHMOOD NAJMI \\ Ph. D. Scholar of Economics, \\ The Superior University, Lahore, Pakistan
}

\begin{abstract}
This paper aims at investigating the impact of cultural ads on the consumer behavior towards different products like their attributes towards brand, attribute towards advertisement and purchase intention. Culture plays very vital role while selecting the products. This paper tests the efficiency and importance of the cultural ads. Data has been collected from 160 respondents in questionnaire form. Factor analysis, ANOVA, Regression Analysis and CronBach's Alpha were run in SPSS to verify the devised model. Significant results were deduced to enforce the hypotheses that cultural ads do have impact on attributes towards brand and attribute towards advertisement, but not for purchase intention. Further research can be conducted in this research by changing the demographics of respondents and expanding the research horizon to check the significance of cultural ads in marketing and promotion. Further aspects of culture can also included to determine how culture can have positive impact on purchase intentions.
\end{abstract}

Keywords: Attributes towards Brand, Attribute Towards Advertisement and Purchase Intention, Cultural Ads

\section{INTRODUCTION}

In all countries all over the world, the trend is to reduce restrictions within the local economy. Increase in the globalization of the market was necessary to capture capitalist practices as an effort to establish a liberal economy and change beliefs in order to form more international economy. Today increase in capitalist style along with the changes in the commercial practice philosophy, have a great impact on social relations and peoples' way of living in our economy, which leads to recognize the importance of research in 
consumer behavior, and in particular the consumers' attitude towards advertising, which will facilitate studying the effects and functions of advertising in society.

Moreover, culture affects advertising in various ways. Religion plays an important role in influencing the culture or society in many countries (Hassan, 1990), while there many other countries too where social system prevails advertising (Gordon \& Lima-Turner, 1997). For instance, the reforming of the Russian economy in the past years has transformed advertising (Andrews \& Durvasula, 1994) .

Apart from that, the change in culture is not restricted to a particular culture or society. The change in culture is small and they modified over time and alterations are spread from culture to culture. And it was identified that cultures have direct impact on consumer attitudes towards advertising. Researchers have investigated these changes in culture through cross-cultural studies, as these modifications can be generalized towards a group of countries that share the same cultural approach. There are a few cross-cultural studies related to attitudes towards advertising which encourage more studies (Waller, Fam, \& Erdogan, 2005).

In past decades, the advertising sector has experienced significant growth (Redah, 1997). As the competition and globalization is increased nowadays, firm's market share and revenue dramatically increased due to increase in advertising. All these studies suggest the increasing importance of the impact of culture on the consumer perception and attitudes towards advertising.

Now the trend of developing worldwide customer and employee bases is increased in the companies. Therefore, customers are from very diverse and different cultures, and marketing managers have to establish and elaborate their own advertising strategies as they cannot afford to ignore these cultural differences and variety of related values (Diaz, 1985).

This study analyzes the consumers' perspective and examines consumer's perceptions on the values of different types of ads with the aim to understand the perceived differences between the cultural ads and non-cultural ads. This can be utilized by welldesigned directional online and other ads. This research will provide practical suggestions on how to design effective ads to fully utilize the advantages of the online medium. 
This study aims to extend previous studies that have researched the attitude towards advertising and further examines impact of cultural and non-cultural advertisement on the attribute towards advertising, attribute towards brand and purchase intentions?

\section{LITERATURE REVIEW}

Advertising has become an important part of our lives as breathing. When we turn on the TV, open our mailbox, drive down the street, pick up our phone, or during Internet surfing we come across many important facet of advertising (Calfee, 1998). Though there are now many mediums of advertising like internet, social media, print media, etc, but still there is strong impact of television advertisement on the society. A country's culture can be understood through its advertisement. It is convenient for marketing professionals to promote culture through advertisements. The main purpose here is to create value and image for the brand by promoting culture. Promoters blend the brand position and the values of the prospects to create most impact during the development of advertisement campaign (Mukherjee, 2009).

Advertising has a great effect on our society as a whole. It has developed into one of our cultures primary sources for information, solutions, ideas, and entertainment. Advertisers by using resources like television, magazines, newspapers, billboards, the Internet, etc. reach a broad spectrum of people, and it is easy to see how they can affect the society (Calfee, 1998).

Culture is very important for the success or failure of the product as customers are emotionally attached with it and it dominates while making decision in choosing the product (Janjua, 2012). Culture is basically the set of values, perceptions, wants and behaviors which people or society learn from family and from some other institutions (Kotler \& Armstrong, 1999). The culture have become a vital factor in advertising as it explains the consumer behavior of impulsive buying which got influence if the consumer get reorganization depending upon their culture which includes their belongings, customs, emotional attachment to their religion (Kacen \& Lee, 2002).

As each society has its own unique set of values, perceptions, wants and behaviors like folklore, popular idioms, customs, myths, cultural practices and conventional empirical knowledge associated with its immediate environment, which is named by Gramsci as cultural common-sense. The impact of culture have been researched by many 
researchers including its impact on developing promotional tools (Fam \& Merrilees, 1996) and on strategies required to develop brand image consumer's mind (Roth, 1992). And the result of such studies shows that the culture factor have became very vital source to get the consumer's attraction if the advertisement content developed with the consideration of the culture of the consumers which the advertisers are going to target (Tse, Belk, \& Zhou, 1989).

Asian countries having Asian culture are more focused towards the name of the brand, maintaining face and harmony of the group while purchasing the luxurious products (Ahuvia \& Wong, 1998). In Pakistan some of the advertisers have been found promoting the local cultures yet some are negligent regarding the matter. Some marketing are adept in using advertising to promote culture. There are various languages in Pakistan along with different casts. Values are different across the nation based on the language and casts. However, some values are same everywhere.

Marketers usually use the prominent and dominant culture of Pakistan during their advertisements in different media. They use traditional family values in the advertisements. These advertisements depict joint family gatherings like tea time, dining time etc to focus on the "family". But on the other hand there are some brands what they predicting is not the culture of Pakistan like gender abuse and discrimination prevails all over the world but we also know that it doesn't happen this frequently.

Consumer values are the continuous and frequent source of concern for philosophers and social critics. Advertising and culture, summarizes from the work of a number of critics two representations of consumers entangle in the "consumer" or material culture. In one case, participants in consumer culture are seen as philistines; acquisitive and upwardly mobile, with sturdy character, perhaps, but bad values, working long hours and saving money to satisfy obsessive longings for whatever the next prestigious consumer good may be-the stereo, the home computer, the food processor, the videotape recorder (Schudson, 1984).

In his view, globalization is changing the world into a 'homo cultural' market place where all customers, irrespective of their culture, can be convinced by the same advertising appeals and values. And such homogenization of culture would have a number of important advantages from a marketing point of view for advertisers (Levitt, 1983). 
Advertisers make such ads that can reach a large audience with simple and small messages that present different opportunities and offers or incentives to allow consumers to understand what that particular product is, what its objectives, how it functions and how it relates to all the other similar products which is the main function of advertising that leads to communicate with specific audiences (Fill, 2006). The main objective of the advertising is to change or influence the consumer's attitudes towards product that consumer should focus on the idea that he would buy their product or service instead of any other product or service and eventually become habitual of that product or service (Jefkins, 1985). Advertising is not a simple concept that can be merely explained by answering that how does advertising works because advertising is very wide and broad idea which focuses on the concept of persuasion or communication (Corstjens, 1990).

Many researchers link the appeals used in advertising with the cultural dimensions, such as "Eastern" and "Western" values (Cheng \& Schweitzer, 1996). Today consumers appear to be more in favor of culturally congruent appeals and styles (Dahl, 2004). We can say that TV advertising is not an effective way to promote traditional values. With these Pakistani samples, we cannot say that those brands were successful in promoting their products which are not predicting the culture of Pakistan.

In this study, we take a consumers perspective and examine consumers perceptions on the values of different types of ads. Advertising can be classified into two categories: brand building and directional (Fernandez \& Rosen, 2000). Brand building advertisements focus on the establishment of a positive image of that product or service and to create demand for a product or service that leads to eventual purchase (Barrow, 1990). Our aim is to understand the differences between the non-cultural advertising and traditional/cultural advertising.

Such researches aims to provide a deeper and detailed explanation of observed differences in advertising through linking appeals and observations to cultural dimensions, and hence tries to forecast value and appeal differences in various countries. It usually tries to explain the observed differences and similarities by using fundamental dimensions of cultural variability. This research illustrates the relationship between advertising and culture in general - often with the implicit assumption that advertising itself is necessarily reflective of culture (Samiee \& Jeong, 1994). 


\section{A. ATTITUDES TOWARDS ADVERTISING}

Based on the above literature about attitudes towards advertising, a research framework have been constructed which show the relationship among product information and the social image which shows the relationship between general attitude towards advertising. Two sets of hypothesis are developed from the above framework (Polly \& Mittal, 1993).

$H_{1}$ : Cultural advertisement has positive impact on the attribute towards advertising than non-cultural advertisement.

\section{B. ATTITUDES TOWARDS BRAND}

Attitude toward brand is a "predisposition which shows the response of the customer in a favorable or unfavorable way to a particular brand after its advertising has been shown to the individual" (Phelps \& Hoy, 1996). Many studies found that attitude towards brand had a positive and significant effect on the purchase intentions for the particular product. (Mitchell \& Olson, 1981).

$\mathrm{H}_{2}$ : Cultural advertisement has positive impact on the attribute towards brand than noncultural advertisement.

\section{PURCHASE INTENTION}

Purchase intention can be defined as how likely it is that the individual would purchase the product (Phelps \& Hoy, 1996) or the predisposition to buy a certain brand or product (E. \& A, 2004). Purchase intention has been found to play an important role as predictor of the consumer's purchase behavior (Shimp \& Gresham, 1985)

$H_{3}:$ Cultural advertisement has positive impact on the purchase intention than non-cultural advertisement.

\section{THEORETICAL FRAME WORK}

Cultural advertisement and non-cultural advertisement are independent variables. Cultural advertisements depend on the attribute toward brand, price and purchase intention of the customer. The cultural advertisement campaign pushes the customer to purchase the product that fits their culture. Non-cultural advertisements depend on the attribute toward brand, price and purchase intention of the customer. Non-culture advertisement 
enables to understand the other culture. Non-cultural advertisement also pushes the customer intention. But it has least effect on customer attribute toward brand, price and purchase intention as compared to cultural advertisements.

Attribute toward brand, price and purchase intention depends on the independent variables (Cultural \& Non Cultural Advertisement). The stronger the advertisement campaign the stronger the relationship between customers. The advertisement campaign based on the culture, the greater the outcome from that campaign.

\section{Figure 1}

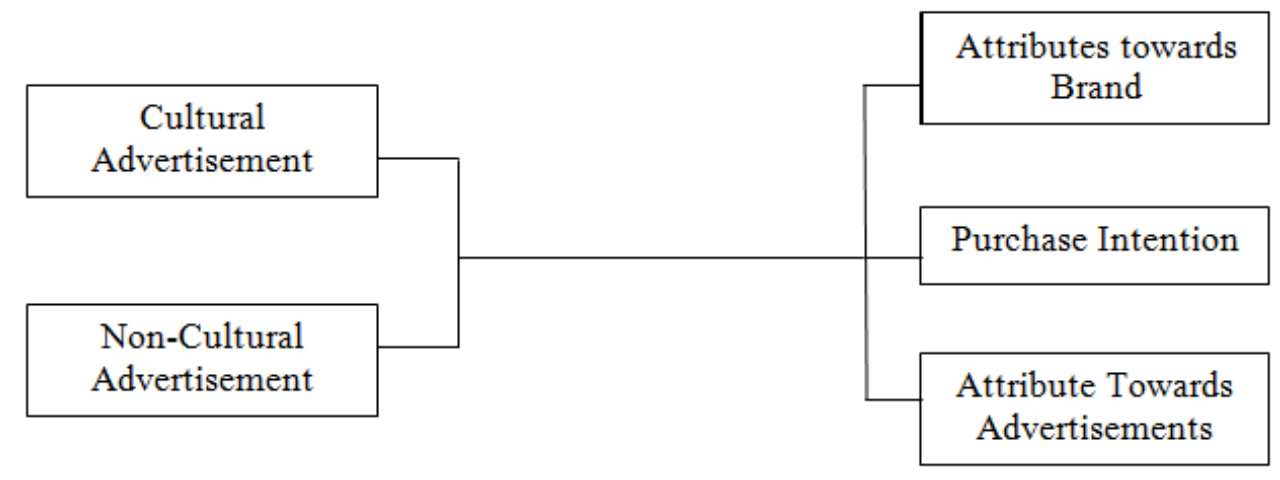

\section{RESEARCH METHODOLOGY}

\section{A. SAMPLE}

A questionnaire survey was developed to gain insight of the consumers' behavior towards advertisement, brand and their purchase intentions (Zafar \& Rafique, 2012). Questionnaires were developed for the surveys which were distributed in different universities, households and business personals. To obtain the relevant information, population surveyed consisted of students, housewives and people from all walks of life. A total of $\mathbf{2 0 0}$ questionnaires were administered to potential respondents chosen from various areas of Lahore, Rawalpindi and Islamabad by using non-probability sampling technique. A total of 160 usable questionnaires were returned, giving a response rate of $85 \%$. Demographics were also included in order to control their effect while measuring consumers' attitudes.

Students show more favorable attitude towards advertising in a number of dimensions than the other people (Shavitt, Lorey, \& Haefiner, 1998). So there is a significance impact of advertisement towards general attitude. The research conducted highlights that advertisement could be done by using cultural ads as well as non-cultural 
ads, women and men perceived it differently. The researcher has different affect on advertisement which has a different impact on their attitudes and beliefs.

\section{B. MEASURES USED FOR QUESTIONNAIRE}

The questionnaire was designed to measure general attitude of consumers towards advertising, brands and their purchase intentions. Likert scale was used for independent variable attitude towards advertising, attitude towards brand and purchase intentions ranging from 1 to 7 where 1 is coded as "very bad", "very uninteresting", "very dislike", "very uncreative", "very uninformative" and "very unbelievable" and 7 is coded to "very good", "very interesting", "very creative", "very informative" and "very believable" for attitude towards advertising and attitude towards brand and for measuring purchase intention 1 is coded as "very unlikely" and 7 is coded to "very likely".

\section{STATISTICAL TECHNIQUE}

There are many types of research. We used hypothesis testing for our research methodology. In hypothesis testing there are two categories, i.e. measure of difference and measure of association (Zikmund, Babin, Carr, \& Griffin, 2012). We are in the category of measure of difference. In hypothesis testing measure of the difference are further subdivided into 4 types. We are using the measure of the difference with two groups and number of variables. SPSS has been used to analyze the data. In the first stage, validity of the questionnaire has been checked by applying Skewness and Kurtosis test which measures normality of the data. In the second stage, reliability of the data has been checked by applying Cronbach's Alpha which measures internal consistency or average correlation of items in a survey instrument to gauge its reliability. Independent sample t-test (mean) will be used for parametric test and Mann Whitney U-test (median) for nonparametric test (Zafar \& Rafique, 2012).

\section{FINDINGS AND RESULTS}

The findings of the study are based upon frequency distribution and concluded as; We have collected data from 160 respondents in which $62 \%$ are male respondents and $38 \%$ are female respondents in which frequency of male respondents is 99 and of female respondents is 61 , consisting of $94 \%$ respondents from student class and remaining are bankers, businessmen, CEO, professors and students. Data is divided into two halves .i.e., $50 \%$ on cultural ads and $50 \%$ on non-cultural ads. 
Table 1: Test of Normality of Data

\begin{tabular}{ccc}
\hline Variables & Skewness & Kurtosis \\
\hline Attitude towards ads & 0.11 & -0.81 \\
\hline Attitude towards brand & 0.45 & 1.25 \\
\hline Purchase intentions & -0.26 & 0.33 \\
\hline
\end{tabular}

Variables named attitude towards ad is measured on 6 items, attitude towards brand on 6 items and purchase intentions on 3 items and the data collected from 160 respondents is normally distributed as the value of test of descriptive lies between -2 and +2 and on the basis of Skewness and Kurtosis test data is declared to be normally distributed.

Table 2: Reliability Analysis

\begin{tabular}{ccc}
\hline Variables & Number of Items & Cronbach`s Alpha \\
\hline Attitude towards ads & 6 & 0.89 \\
\hline Attitude towards brand & 6 & 0.71 \\
\hline Purchase intentions & 3 & 0.67 \\
\hline Full Scale & $\mathbf{1 5}$ & $\mathbf{0 . 8 7}$ \\
\hline
\end{tabular}

Reliability test of the entire item is run and measured through Cronbach alpha where alpha value is 0.05 and there is $95 \%$ confidence interval. It calculates the intervariable reliability. The scale was tested for reliability by using Cronbach's Alpha. The overall values of Cronbach's alpha for variables are above 0.6 which means that the constructs were reliable to measure the impact. Whereas alpha value of dependent variable are within the acceptable range and means that individual constructs were reliable to measure the parameters of impact.

Table 3: Exploratory Analysis

\begin{tabular}{cccc}
\hline Variables & $\begin{array}{c}\text { Bartlett`s Test } \\
\text { (p-value) }\end{array}$ & $\begin{array}{c}\text { Variance } \\
\text { Explained }\end{array}$ & $\begin{array}{c}\text { Components } \\
\text { Extracted }\end{array}$ \\
\hline Attribute towards ads & 0.00 & 64.85 & 1 \\
\hline Attribute towards brand & 0.00 & 53.51 & 1 \\
\hline Purchase intentions & 0.00 & 62.55 & 1 \\
\hline
\end{tabular}

Exploratory analysis is done to know how many factors combine to form one variable. First variable named attitude towards ad has 6 items and it is loaded in 1 component, second variable is attitude towards brand that has 6 items and it is also loaded in 1 item and the third variable is purchase intention that has 3 items and it was loaded in 1 component. 
Table 4: Levene's Test for Equality of Variance

\begin{tabular}{ccc}
\hline Variables & F-Value & P-Value \\
\hline Attribute towards ads & 0.68 & 0.41 \\
\hline Attribute towards brand & 0.89 & 0.35 \\
\hline Purchase intentions & 0.29 & 0.59 \\
\hline
\end{tabular}

Levene's test is specially conducted for equality of variances. If the p-value in levene's test is greater than 0.05 then we can assume that there is equal variance and we will take first value of the t-test and vice versa. As in this test, $p$-value of attitude towards ad and attitude towards brand is less than 0.05 so we will take second value of the t-test and assumed it to be equal variance not assumed. And for the third variable, that is purchase intention, $p$-value is greater than 0.05 we would take it equal variance assumed and take the first value.

Table 5: Independent Sample T-Test

\begin{tabular}{ccc}
\hline Variables & T-Value & P-Value \\
\hline Attribute towards ads & 5.89 & 0.00 \\
\hline Attribute towards brand & 5.34 & 0.00 \\
\hline Purchase intentions & 1.41 & 0.16 \\
\hline
\end{tabular}

Independent sample t-test is run to check the hypothesis that weather we have to accept the hypothesis or reject it. If the $p$-value is less than 0.05 the hypothesis will be accepted and if the $p$-value is greater than 0.05 then we would reject the hypothesis. As the values of $p$-value in the independent $t$-test of Attribute towards ads and Attribute towards Brand are less than 0.05 we would accept the hypothesis $\mathrm{H}_{1}, \mathrm{H}_{2}$ and reject the hypothesis $\mathrm{H}_{3}$.

\section{CONCLUSION}

As the hypothesis $\mathrm{H}_{1}$ and $\mathrm{H}_{2}$ accepted it means that the cultural advertisement has positive impact on the attribute towards advertising and attribute towards brand than noncultural advertisement. And as the hypothesis $\mathrm{H}_{3}$ was rejected, it shows that the purchase intentions did not have positive impact on cultural advertisement.

For this reason it is very important to have proper knowledge about the culture of the customers of that demographic region which the marketer will going to focus and it will also helpful while designing the advertising campaign for both local and international markets. 
The firms indicated that cultural various exerted varied influence on marketing strategies used by the multinational firms, which called for the use of specific strategies for particular situations and influences. The firms also indicated that marketing strategies were adopted to purposely overcome competition for more market shares and improved sales, and to stand the test of the ever-changing trends as it affected demand and supply. Some of the strategies included the use of quality products, frequent advertisement in local media, ideal pricing structure, reward sales promotion and new product innovations.

\section{A. IMPLICATIONS}

The purpose of this study was to get more insight in the adequate use of advertising under the influence of the culture. In this research, consumer's perspective was analyzed and examined consumers perceptions of different types of ads with the aim to understand the perceived differences between the cultural and non-cultural ads. This research will contribute to a better conceptual understanding of consumers' perceptions by extending the existing frameworks. Meanwhile, the study can provide practical suggestions on how to design effective ads. All firms had adopted some useful remedies to overcome cultural influences affecting their operations. These include: product adaptation, promotional adaptation and new product innovation with the above in use.

\section{B. LIMITATIONS}

A limitation of this research is that it has not covered all the segments of the market. If the data would collected from larger number of respondents the results might be different or diversified or represent more accurate and reflective information regarding culture aspects on consumer behavior.

\section{FUTURE RESEARCH}

This research still has more room for improvement. Further research can be conducted in this research by changing the demographics of respondents and by targeting the different segment of the market or by expanding the research horizon to check the significance of consumer behavior by analyzing and comparing the consumers belonging to completely different cultures and how culture can influence the purchase intentions in marketing and promotion. 


\section{REFERENCES}

Ahuvia, A., \& Wong, N. (1998). The effect of cultural orientation in luxury consumption. Advances in Consumer Research .

Andrews, J. C., \& Durvasula, S. (1994). Testing the cross-national applicability of U.S. and Russian advertising beliefs and attitude measure. Journal of Advertising , 71-83.

Barrow, P. (1990, Spring 15). Does Your Advertising Direct or Intrude? (C. Manage, Interviewer)

Calfee, J. E. (1998, April 1). How Advertising Informs to Our Benefit. Consumers' Research Magazine .

Cheng, H., \& Schweitzer, J. C. (1996). Cultural values reflected in Chinese and U.S. television commercials. Journal of Advertising Research , 27-44.

Corstjens, J. (1990). Strategic Advertising: . A Practitioner's Handbook, Oxford, Heinemann.

Dahl, S. (2004, January 12). Social Science Research Network. Retrieved July 10, 2015, from Social Science Electronic Publishing, Inc.: http://papers.ssrn.com/sol3/papers.cfm?abstract_id=658202

Diaz, R. M. (1985). Advertising effectively in foreign markets. SAM Advanced Management Journal, 12-20.

E., B. G., \& A, B. M. (2004). Advertising and Promotion an Integrated Marketing Communication Perspective. New York.

Fam, K., \& Merrilees, B. (1996). A promotion mix budgeting model for retailing. International Review of Retail, Distribution and Consumer Research , 6, 25-37.

Fernandez, K. v., \& Rosen, D. L. (2000). The effectiveness of information and color in yellow pages advertising. Journal of Advertising , 61-73.

Fill, C. (2006). Simply Marketing Communications. Financial Times Prentice Hall.

Gordon, M. E., \& Lima-Turner, K. D. (1997). Consumer attitude toward internet advertising a social contract perspective. International Marketing Review , 362.

Hassan, A. (1990). Saudi citizens' attitude towards advertising: A research in Riyadh city. Riyadh: King Saud University.

Janjua, B. N. (2012, February 15). An Investigation to the Impact of Culture on Advertisement. WALES, United Kingdom.

Jefkins, F. (1985). Advertising . The M\&Handbook Series Pitman Publishing.

Kacen, J. J., \& Lee, J. A. (2002). The Influence of Culture on Consumer Impulsive Buying Behavior. Journal of Consumer Psychology , 163-176.

Kotler, P., \& Armstrong, G. (1999). Princilples of Marketing. New Delhi: Prentice-Hall.

Levitt, T. (1983). The globalization of markets. The International Executive , 17-19.

Mitchell, A. A., \& Olson, J. C. (1981). Are product attribute beliefs the only mediator of advertising effects on brands attitude? Journal ofMarketing Research , 18 (3), 318-331. 
Mukherjee, D. (2009, August 6). Social Science Research Network. Retrieved July 10, 2015, from Social Science Electronic Publishing, Inc: http://papers.ssrn.com/sol3/papers.cfm?abstract_id $=1444814$

Phelps, J. E., \& Hoy, M. G. (1996). the Aad-Ab-PI relationship in children: the impact of brand familarity and measurement timing. Psychology \& marketing , 13 (1), 77101.

Polly, R., \& Mittal, B. (1993). Here are the beef factors, determinants, and segments in consumer criticisim of Advertisising. Journal of Advertising , 57 (7), 99-114.

Redah, R. (1997). Advertising expenditure in GCC country. Conference of Advertising and Advertiser in GCC. AlSharga.

Roth, M. (1992). Depth versus breadth strategies for global brand management. Journal of Advertising , 23 (1), 97-110.

Samiee, S., \& Jeong, I. (1994). Cross-cultural research in advertising: An assessment of methodologies. Journal of the Academy of Marketing Sciences , 205-217.

Schudson, M. (1984). Embarrassment and Erving Goffman's idea of human nature. Theory and Society , 633-648.

Shavitt, S., Lorey, P., \& Haefiner, J. (1998). Public attitude towards advertising: More favorable than you might think. Journal of Advertising Research , 38 (4), 7-2.

Shimp, T. A., \& Gresham, L. G. (1985). Attitude towards the advertisment and brands attitude: a classical conditioning perspective. Journal of Advertising , 14 (1), 1018.

Tse, D., Belk, R., \& Zhou, N. (1989). Becoming a consumer society: a longitudinal and cross-cultural content analysis of print Ads from Hong Kong, the People's Republic of China and Taiwan. Journal of Consumer Research , 15 (1), 457-72.

Waller, D. S., Fam, K., \& Erdogan, B. (2005). Advertising of controversial products: A cross-cultural study. The Journal of Consumer Marketing , 6.

Zafar, Q.-U.-A., \& Rafique, M. (2012). Impact of Celebrity Advertisement on Customers' Brand Perception and Purchase Intention. Asian Journal of Business and Management Sciences , 56-67.

Zikmund, W., Babin, B., Carr, J., \& Griffin, M. (2012). Business research methods. Cengage Learning. 